clearly to science as a whole. Salomon even implies (page 183) that competition for recognition has become intense only since the 1920s. I suspect he misattributes the historical transformation: it is not so much the character of science which has changed as the writing about science which has become more sophisticated and realistic.

$\mathrm{He}$ is not critical enough of the discovery push type of thinking which sees technological innovation as the result of pure research. Historians -even non-Marxist ones-have realised that it is at least as illuminating to analyse the technological roots of science as the scientific roots of technology, and work on modern industrial innovation indicates that today, too, need pull is more important than discovery push and that the inputs from science into technology are in fact rather tenuous.

By the time a book appears in a second language, three years after its original publication, it should be free of historical howlers such as the one about "the steam engine, of which Watt had the first idea as early as 1765" (page 27). Readers used to the downto-earth directness of the best English writings on the subject may find that too many of the Franco-English sentences need rereading before they yield a meaning.

$$
\text { F. R. JEVons }
$$

\section{Making the best of it}

Optimum Structures. By W. S. Hemp. Pp. xii +123 . (Clarendon: Oxford; Oxford University: London, May 1973.) $£ 7.50$ boards; $£ 3.50$ paper covers.

IN recent years a great deal of attention has been focused on optimal or optimum structures. Such systems have their components so arranged as to minimise internal forces and so dimensioned as to maintain uniform stresses. Originally this field of study proved to be of special interest to aircraft designers, but recently civil and structural engineers have also turned their attention to it. The basic principle of optimisation applies to all classes of structures, and the recent trend towards improved design of structures of minimum weight obtained at a minimum cost gathers momentum.

To achieve these aims a detailed knowledge of various factors and a clear picture of their mutual interdependence are required. Optimisation can produce the desired result and it can be described as a procedure used by the designer to decide on the one specific solution in a defined set of possible alternatives that will best satisfy a selected criterion. In the past the optimisation of structures has required lengthy and time-consuming calcula- tions. The advent of digital computers is changing this, enabling the designer to compare many solutions in his search for the optimum structure. At the same time the interest grows in the fundamental philosophy regarding optimum structures.

Although there are already several papers published on this topic, Professor Hemp's book is unique, not only because it deals at great length with the basic principles of the analysis of optimum structures, but also because it incorporates a great deal of fundamental and highly original work of the author. Whereas most of the published articles deal with numerical methods, this book is mainly concerned with the derivation of the general principles of optimum structures using linear programming and the calculus of variations. It covers the treatment of pin-jointed frameworks, beams, circular sandwich plates, Michell's structural continua and plates loaded in their planes. Optimisation of structures can very easily become highly sophisticated and extremely difficult depending on the number of constraints or independent parameters considered in the analysis.

Although the treatment by nature is highly mathematical, the author has succeeded in producing a lucid exposition of the up-to-date methods of determining structures of least volume of material. $\mathrm{He}$ pays special attention to the use of Lagrangian multipliers. This is a book which many research workers and some designers will find extremely valuable in their search for the ideal structural form.

\section{Z. S. MaKowSKI}

\section{Currents in insulators}

The Theory of Electrical Conduction and Breakdown in Solid Dielectrics. By J. J. O'Dwyer. (Monographs on the Physics and Chemistry of Materials.) Pp. ix +317. (Clarendon: Oxford; Oxford University: London, September 1973.) $£ 10$.

ONE might think that the subject of 'currents in insulators' was a contradiction in terms. This is not so: insulators have a wide forbidden band and hence often block the transport of current. But while it takes effort to introduce carriers into the conduction band, once they are there they run down potential slopes in the conventional way unless arrested by imperfections. Because of the difficulties of experimental study, the theory of charge transport in dielectrics is not so advanced as in semiconductors and metals. Injection of charge into thin-film insulators is, however, now seen to be potentially useful and this should raise the level of research performed.

The other technologically relevant field is the one treated in this book: when insulators are stressed to a very high field (over $10^{8} \mathrm{~V} \mathrm{~m}^{-1}$ ), new phenomena occur which turn the material into a good conductor, though perhaps only over a limited part of the area exposed to stress. This part then carries an increasing current until the material overheats and is destroyed. In highvoltage technology, these effects must be minimised where possible. For this, one must understand the conduction phenomena occurring at the onset of breakdown. The object of this book is to lay out, in a concise manner, the various pieces of theory and research concerning conduction in insulators which aid this understanding and then to build on these concepts a picture of the complex events leading to the final catastrophic breakdown.

The author has, on the whole, achieved these limited aims with a commendable economy of space. After a useful initial survey chapter, which sets the scene well, the reader is led, with little deviation, through the several types of conduction possible in insulators. The research results of many workers are quoted for cases in which it is advisable to show how a particular mathematical model is embodied in real life. So far, so good ; however, the author is a specialist in the field of breakdown phenomena (this book is actually a greatly broadened form of a 1964 book outlining his own theory of breakdown). Perhaps because of this, he seems to lean over backwards to be impartial and, as a result, withholds any overt judgments on the relative merits of the experiments and theories described. Not only does he seem to be saying "now judge for yourself", but one is also left with the erroneous impression that every model ever devised for conduction in insulators is equally true and common, even though some do, in fact, conflict. It is a pity that the benefits of a highly informed point of view were so clearly withheld.

There is thus little to disagree with in this book. It is a good, dispassionate record of published fact. A few omissions can, however, be sensed by scanning the author and subject indexes; there is no entry for 'photoinjection' or 'filamentary conduction', although both loom large in charge transport through thin-film insulators-a field which one would expect to be covered in a book of the aims stated. Neither are the investigations of Berglund, Powell or Nicollian on various types of injection into silicon dioxide films, or the work of Dearnaley or Harrop on filamentary and a.c. conduction phenomena, given any mention. In general, the book thus has a bias towards 'bulk' experiments and places little reliance on thin films as media for elucidating transport phenomena-an unfortunate blind spot, since Lynch has recently built on such 